\title{
Polish Fans' Emotions during EURO 2012
}

Authors' Contribution:

A - Study Design

B - Data Collection

C - Statistical Analysis

D - Data Interpretation

E - Manuscript Preparation

F - Literature Search

$\mathrm{G}$ - Funds Collection

\author{
Ina Wilczewska ${ }^{(B, C, ~ D, ~ E, ~ F), ~ P a w e ł ~ B o s k i ~}{ }^{(A, ~ C, ~ D, ~ E, ~ G) ~}$ \\ University of Social Sciences and Humanities, Warsaw, Poland
}

Key words: football, Championships, fan, emotions

Material/Methods: Over 700 individuals took part in 3 waves of the study which corresponded to Polish

\section{Abstract}

Background: The study was conducted during the 2012 UEFA European Football Championships between 8 and 19 June. It aimed at longitudinal investigation into the dynamics of Polish fans' emotions related to the performance of their national football team. Special focus was laid on investigating the evaluation of organizational preparedness to the tournament as a broader context for sport events, and relating it to fans' emotions. team's games in the group stage of the tournament. Participants were contacted immediately after the final whistles, receiving e-mails with links to on-line questionnaires. In the first wave, respondents filled in the scales of national pride and shame, interest in football, enthusiasm and skepticism after the opening match and anticipatory emotions before the second match. In the second wave, outcome-related emotions were measured as real (the draw score) and as counterfactual (victory and loss). In the third wave, scales concerning Poland's final defeat were employed. Each wave included measures of fans' behavior during the game.

Results: The experience of a real (with the Czech Republic) or imaginary (with Russia) defeat was determined by pre-match anticipatory excitement and the intensity of expressive behavior during the match. Satisfaction with the tournament organization and general enthusiasm about the event affected the emotional reaction to the outcome draw (with Russia) as well as to constructive coping with the eventual defeat.

Conclusions: Draw is experienced by football fans as qualitatively different from a loss or a victory. Defeat of a team or its victory are highly emotional results whereas a draw leads to more balanced reactions and derives its meaning from the context of the event.

\footnotetext{
Word count: 4.344

Tables: 1

Received: January 2013

Figures: 3

Accepted: February 2013

References: 14

Published: March 2013

Corresponding author:

Ina Wilczewska

University of Social Sciences and Humanities, Faculty of Psychology

03-815 Warsaw, Chodakowska 19-31

Phone: +4822 5179812

E-mail: ina.wilczewska@swps.edu.pl
} 


\section{Introduction}

The European Football Championships of the last year, commonly referred to as EURO 2012, were held in Poland and Ukraine. It was a unique experience for the country and for the general population of Poland, surpassing regular football fans. Preparations for this event lasted five years and made the main theme in the county's political life and public discourse during that time. Those preparations comprised a substantial improvement in road - transport infrastructure and the construction of new stadiums. The three weeks of the championships in June 2012 were regarded in advance by general public and the media as the crucial test for the government, and for the country as the whole, in meeting the European standards. The international image of Poland as an efficient, well organized, and friendly country was at stake.

International events of this scale evoke strong social emotions of a general nature: country pride level, self-esteem or their opposites - shame and disrespect [1]. Another important source of emotions has to do with sports performance of the national team. This team represents "us", i.e. all compatriots; consequently, its victories or defeats are experienced as if they were "ours" [2]. These two are good reasons for expecting extra-large audience to watch the games and to show other forms of interest in the tournament. Indeed, these are the factors which explain the record high numbers of spectators watching the games. Data collected by Nielsen Audience Measurement for Polish television allowed an estimated 14 million audience watching each of the three matches played by the Polish national team (on average) [3]. A situation like this, which is regarded as important and evokes emotional involvement in a substantial proportion of the population, deserves to be studied.

Existing psychological studies have focused on fans' emotions and, conducted during international tournaments, they have not taken into account the specific atmosphere preceding the event. Emotions have been analyzed in the context of national identity [4] or during the ups and downs in team performance [5], but never in the context of state-level preparations to the tournament. Thus, one of the aims of this study was to examine social emotions connected with country level tournament preparations, and sports emotions related to the national team performance on the pitch. The following research question was posed: Would the emotions associated with the evaluation of the country's preparations for the EURO 2012 be related to the emotions connected with games' outcome?

The second objective of this study was to examine in depth the nature of fans' emotions experienced during the matches played by the Polish national team. The specificity of sport tournaments is reflected in fans' longitudinal emotional involvement. Since the tournament consists of several stages (group stage, quarter-finals, semi-finals and the final), which the victorious team has to pass, fans respond to the dynamics of this process accordingly.

The group stage consists of three matches played by each of the four teams of the group, and therefore it has its own dynamics and drama. The scores achieved in these three matches decide whether a team qualifies for the quarterfinals. It frequently happens that the group result remains unclear until the last match of the group stage. This is why the fans' emotional reaction to the team performance during the group stage is more complex than during any singular sport event. This process starts with anticipatory emotions well before the tournament has begun, it intensifies and continues while the team is playing, and ends with a display of emotions related to the final score. Moreover, ruminations may follow after the defeat, while the next round triggers a new circle, starting with new anticipatory emotions.

Not many studies have tried to capture the processual character of fans' emotional experience during football tournaments. Jones et al. [5] analyzed Spanish and English fans' emotional reactions to their national teams' performance during the 2010 Football World Cup. They collected data at several points in time: pre-tournament, post-match (respectively to all games played by national teams) and post-tournament. They observed significant differences in fans' moods as a response to particular matches and provided evidence that positive emotional experience associated with a team's success persists longer than the negative emotional experience associated with a team's defeat. 
It is important to note that the longitudinal aspect of a football tournament corresponds well with processual characteristics of emotional experience. Its anticipatory stage has been well elaborated on in the value expectancy theory of achievement motivation [6, 7, see also: 8]. Expectedness is also one of the components in Scherer's work on emotions [9]. The past time perspective is also present in sport and in the general theory of emotions. Reminiscences of glorious moments or painful defeats are the subject of an individual recall, or can be facilitated by the media when such moments of matches which had taken place decades ago are refreshed.

The processual and circular approach to tournament emotions experienced by fans is illustrated in the following flow chart (Fig. 1).

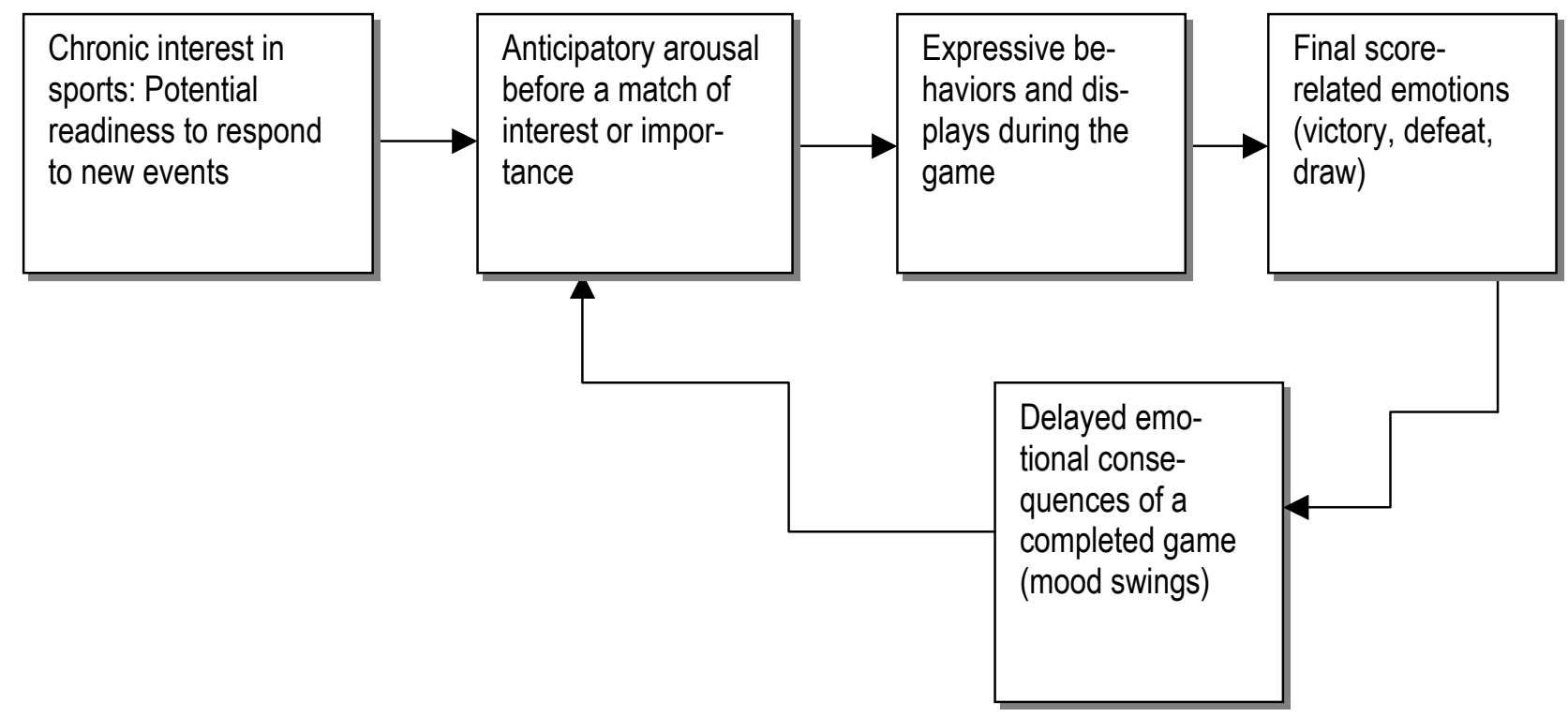

Fig. 1. The flow chart of fans' emotional process during tournament championships

In the present study we wanted to widen the knowledge about fans' emotional experience, which can be considered as a process in the context of the tournament. We intended to achieve this by investigating emotions in three phases: (i) pre-tournament emotions associated with the general enthusiastic or skeptical attitude towards the event, (ii) pre- and post-game emotions and (iii) post-tournament emotions associated with the eventual failure of the Polish national team.

We decided to consider pre-game emotions (anticipatory emotions) assuming that they serve as an indicator for the atmosphere between consecutive matches. They can reflect the current situational dynamics within the group and the perceived chances for qualifying for the next round, based on the instantaneous evaluation of the performance of the other teams. We hypothesize that there will be a positive relation between the intensity of anticipatory emotions and the intensity of match result-related emotions.

Football matches in the group stage can end in a victory, loss or in a draw. When reactions to the game result are investigated, success or failure gained the most attention [e.g. 5, 10], and little of it is paid to a draw. Similarly, research on what predicts an emotional reaction to the match result is scarce and the existing studies concern exclusively winning or losing games [11, 12]. Common observation leads to a conclusion that the intensity of emotions related to victory or loss is much greater than in the case of a draw. The latter is an ambiguous result (e.g. a team could have been saved from a defeat, or it lost a chance of a win) and therefore its meaning can be derived to greater extent from contextual aspects. Consistently with this reasoning, the following research question was posed: What are the determinants and correlates of emotional reactions to match results and are they different in the case of a draw and victory or defeat?

Furthermore, the study aimed at investigating fans' behavior during the matches and its relation to their emotional involvement. Most studies concerning sports' fans behavior concentrate on violence and aggression [e.g. 13, 14]. Studies investigating fans' behaviors during the match which 
do not express violence, but still are a core part of their participation in the event are missing. Hence, the following research question was posed: How is fans' behavior during the game related to the anticipatory excitation and to the final score?

\section{Material and Methods}

The longitudinal study was conducted from June 8 to 21, 2012. Its three waves corresponded to the games played by the Polish national team in the group stage of the EURO 2012 tournament. The overall sample consisted of 777 participants from all over the country (though the majority of them lived in Warsaw and Poznań). As planned, sixty percent of them were men, who prevail in population over female football fans. The average age of participants was $34.91(S D=13.45)$, the youngest was 13 years old and the oldest one 78 . Participants were recruited by students of the University of Social Sciences and Humanities who received 50 PLN and additional course credits for delivering 10 e-mail addresses of individuals who agreed to participate in the research. The whole study was conducted on-line. Participants were sent links to their e-mails addresses connecting them to on-line questionnaires. In the case of the two first games: the opening match against Greece and later the match against Russia, e-mails where sent immediately after referee's final whistle. So, questionnaires were available in the following time frames: 8 June 11:30 p.m. 11 June 11:59 p.m. and 13 June 0:30 a.m. - 15 June 11:59 p.m. respectively. The case of the third match against the Czech Republic was different; links where sent over the day after the match and participants could fill in the questionnaires in the following time frame: 19 June 10:25 a.m. - 21 June 23:59 p.m. This difference resulted from the fact that the last wave of the study had not initially been planned. This also had an impact on the sample size, because participants expected to receive an e-mail with a link only twice. 729 individuals took part in the first study wave. In the second wave, data were collected from 716 individuals, mainly those who participated in the first wave but there were also a few new arrivals. For the third wave, e-mails were sent to all individuals participating in the previous two waves, and 394 of them filled in the questionnaires.

All scales used in the research were designed for the purpose of this study. The reason for this was the unique research context and the will to create measures more compatible with people's specific behaviors and emotional reactions to this particular sport event as well as its highly volatile conditions.

Every single scale has been obtained by the use of Principal Components Analysis with Promax rotation, applied to the items which were supposed to tap them. In all scales, except for those described explicitly as different, response format was a five-point Likert scale.

\section{Measures used in the first wave}

Interest in Football. The scale consisted of 4 items pertaining to football watching: live at game arenas and on TV. Its reliability was $\alpha=0.77$.

National Pride vs. National Shame. Two sets, ten-item each, concerned satisfaction and dissatisfaction with the process and outcomes of EURO 2012 preparations. The two-factor structure emerged from the exploratory analysis. The first factor, called National Pride (10 items accounted for $45.8 \%$ of the total variance), consisted of such items as: The appearance of our cities has changed for the better; Poland has proved that it is worth much more than people from other countries had thought; I am proud of the fact that Poland has managed to organize the EURO 2012 so well. The reliability of this scale, as indicated by the alpha coefficient, was 0.92 . The second factor, National Shame (10 items accounted for $9.8 \%$ of the total variance) consists of such items as: Unfortunately, the bad opinions about Poland and Poles have found their confirmations/have been confirmed; We are inept to take care properly of thousands of guests from abroad; Unfavorable stuff is being written and said about us abroad - unfortunately it is all true. The alpha coefficient for this scale was 0.90 .

Tournament Opening Ceremony and the Opening Game: Enthusiasm vs. Skepticism. Two other sets of items addressed the opening ceremony of the games, and their first event featuring Poland against Greece. A two-factor solution was revealed again. Each factor consisted of 6 items. The Enthusiasm scale accounted for $45.8 \%$ of the total variance and had a good reliability, 
$\alpha=0.86$. Sample items of this scale are: I was impressed by the excellent organization of the opening ceremony; It was a wonderful experience to hear / the cheering crowd/ the scream of victory when we scored a goal against the Greeks. The Skepticism scale accounted for $15.9 \%$ of the total variance and had acceptable reliability $(\alpha=0.625)$. Sample items of this scale are: It could have been better planned and executed; The match was of low quality and boring; I did not enjoy watching it.

Anticipatory excitement before the Poland-Russia game. Anticipatory arousal three days ahead of the game was measured with an 11-item scale, of which sample items are: I am excited by this match; Right now, I cannot focus on anything else but this match; I feel the unique atmosphere of this event, which is present all around me. The scale has high reliability of $\alpha=0.89$.

\section{Measures used in the second wave}

Outcome-related emotions were the key variables in wave \#2, following the Poland-Russia game. In order to broaden the scope of measures, we designed three instruments: one for the real game result, and two were counterfactual, i.e. corresponding to the remaining potential (imaginary) outcomes of the game. Depending on the final score, we had three packages to be used. Since the game ended with a 1:1 score, the package actually sent to the participants consisted of drawrelated affective measures, accompanied by scales associated with the Polish team's counterfactual victory and defeat.

Draw. This 6-item scale reliability was $\alpha=0.80$. Examples of items were: We have a reason to be happy; We have a reason to celebrate; Phew, lots of emotions; All chances are still ahead of us; One cannot demand miracles, our guys made a good job!

Victory. This counterfactual scale $(10$ items, $\alpha=0.90)$ expressed emotions after an imaginary victory of the Polish team. Examples of items in the scale were: I feel lots of energy and the will to live; I am so happy, I am in seventh heaven; I want to celebrate, hug everyone and dance.

Defeat. The second counterfactual scale (10 items, $\alpha=0.87)$ expressed emotions after an imaginary loss of the Polish team. Examples of items in this scale were: It is a tragedy; I feel depressed - no will to live; I want to cry; I am ashamed - we were humiliated.

\section{Measures used in the third wave}

In contrast to wave 1 and 2, when the materials had been prepared beforehand, questionnaires used in the third wave were constructed after the last match between Poland and the Czech Republic was over, with the defeat which eliminated the Polish national team from the tournament.

Final Defeat. The obtained 9-item scale was similar to the Defeat scale from the second wave. It referred to the emotions experienced immediately after the game lost to the Czechs. The scale consisted of such items as: I felt depressed - no will to live; I wanted to cry; I could not believe in what had happened, such a disappointment!; I will not be able to function normally during the next days. The scale reliability was $\alpha=0.85$.

Coping. This 10 -item scale referred to constructive ways of delayed coping with the loss. It has been formulated in the form of popular slogans of those days, chanted to up-beat fans' mood and identity. Examples of the items were: We must stay together: Poles, we're still keeping up with you!; I will still proudly wear our national colors; the EURO 2012 continues, we keep staying happy and cheer other teams on. The scale reliability was $\alpha=0.81$.

Despair. This scale reflected a dysfunctional way of dealing with a negative experience. It had 6 items and reliability $\alpha=0.73$. Item sample were: I need peace and solitude, I don't want to talk to people; I feel as if some person close to me died; The losses of the Polish team are very painful for me, I take them personally.

Expressive behaviors during the game. Questions pertaining to spectators' behavior during the match were measured in each wave. Fans usually respond to the events they are watching with instantaneous expressive behaviors; they may celebrate the moments of glory or sink in a mood of disenchantment and despair. The items of Expressive behaviors had the 'yes' /'no' response format. Sample items are: We were drinking alcohol; we were singing; we were wearing national 
colors; we were shouting; we were supporting our guys; we were dancing; we were kissing; we were smoking cigarettes; we were threatening the opponents. The scale had 9 items framed in plural to best capture the accompanying atmosphere and its density in the group environment where the match had been watched. In the third wave most of the items were repeated and a few new were added, such as: We were full of hope in the beginning; We were petrified when the result turned out to $0: 1$. That scale had 11 items. The scale score resulted from summing up all positive answers, so higher scores meant more expressive behavior displayed. The scales reliability was: $\alpha=0.73, \alpha=0.73, \alpha=0.74$, respectively.

\section{Results}

Correlations between variables were examined in the first step of analysis. Relations between variables from the first and the second wave of the study are shown in Table 1, whereas relations between variables from the two first waves and the third wave are shown in Table 2 (because of differences in the sample size).

Tab. 1. Correlations between variables from wave 1 and wave $2(660 \leq n \leq 731)$

\begin{tabular}{|c|c|c|c|c|c|c|c|c|c|c|}
\hline Variables & 2) & 3) & 4) & 5) & 6) & 7) & 8) & 9) & 10) & 11) \\
\hline 1.Enthusiasm & $.12^{* *}$ & $.42^{* *}$ & $.63^{* *}$ & -.42 * & $.64^{* *}$ & $.46^{* *}$ & $.43^{* *}$ & $.20^{* *}$ & $.39^{* *}$ & $.29^{* *}$ \\
\hline 2. Skepticism & 1 & $.11^{* *}$ & -.01 & $.22^{* *}$ & $.15^{* *}$ & -.04 & $.08^{*}$ & $.14^{* *}$ & $.08^{*}$ & .06 \\
\hline 3. Interest in football & & 1 & $.36^{* *}$ & $-.31^{* *}$ & $.54^{* *}$ & $.24^{* *}$ & $.21^{* *}$ & $.13^{\star *}$ & $.33^{* *}$ & $.31^{* *}$ \\
\hline 4. National pride & & & 1 & $-.66^{\star *}$ & $.46^{* *}$ & $.41^{* *}$ & $.29^{* *}$ & .07 & $.24^{* *}$ & $.18^{* *}$ \\
\hline 5. National shame & & & & 1 & $-.35^{* *}$ & $-.32^{* *}$ & $-.13^{* *}$ & .05 & $-.24^{* *}$ & $-.17^{* *}$ \\
\hline $\begin{array}{l}\text { 6. Anticipatory excitement PL- } \\
\text { RU }\end{array}$ & & & & & 1 & $.37^{* *}$ & $.49^{* *}$ & $.39^{* *}$ & $.43^{* *}$ & $.39^{* *}$ \\
\hline 7. Draw PL-RU & & & & & & 1 & $.40^{* *}$ & .05 & $.15^{* *}$ & $.27^{\star \star}$ \\
\hline 8. Victory PL-RU & & & & & & & 1 & $.53^{\star *}$ & $.31^{* *}$ & $.39^{* *}$ \\
\hline 9. Defeat PL-RU & & & & & & & & 1 & $.18^{* *}$ & $.27^{\star *}$ \\
\hline 10. Expressive behavior PL-GR & & & & & & & & & 1 & $.50^{* *}$ \\
\hline 11. Expressive behavior PL-RU & & & & & & & & & & 1 \\
\hline
\end{tabular}

${ }^{*}$ Correlation is significant at the level of 0.05 .

${ }^{* *}$ Correlation is significant at the level of 0.01 .

Tab. 2. Correlations between variables from wave 3 and variables from waves 1 and 2 ( $369 \leq n \leq 372$ )

\begin{tabular}{|c|c|c|c|c|c|c|c|c|c|c|c|c|c|c|}
\hline Variables & 1) & 2) & 3) & 4) & 5) & 6) & 7) & 8) & 9) & 10) & 11) & 12) & 13) & 14) \\
\hline \multirow{2}{*}{$\begin{array}{l}\text { 12. Expressive behavior } \\
\text { PL-CZ } \\
\text { 13. Final defeat PL-CZ }\end{array}$} & $.33^{* *}$ & .03 & $.21^{* *}$ & $.15^{* *}$ & $-.12^{*}$ & $.45^{* *}$ & $.27^{* *}$ & $34^{* *}$ & $.26^{* *}$ & $.53^{* *}$ & $.52^{* *}$ & 1 & & \\
\hline & $.23^{* *}$ & $.15^{* *}$ & $.13^{* *}$ & .06 & .04 & $.37^{* *}$ & .08 & $.47^{\text {** }}$ & $.58^{* *}$ & $.28^{* *}$ & $.31^{* *}$ & $0.46^{* *}$ & 1 & \\
\hline 14. Coping & $.40^{* *}$ & -.07 & $.26^{* *}$ & $.35^{* *}$ & $-.32^{* *}$ & $.32^{* *}$ & $.37^{* *}$ & $.27^{* *}$ & .08 & $.22^{* *}$ & $.18^{* *}$ & $0.20^{* * *}$ & 0.02 & 1 \\
\hline 15. Despair & $.24^{* *}$ & .13 & $.28^{* *}$ & $.14^{* *}$ & .00 & $.43^{* *}$ & .07 & $.40^{* * *}$ & $.45^{* *}$ & $.19^{* *}$ & $.25^{* *}$ & $0.27^{* *}$ & $0.64^{* *}$ & 0.01 \\
\hline
\end{tabular}

${ }^{*}$ Correlation is significant at the level of 0.05 .

${ }^{* *}$ Correlation is significant at the level of 0.01 . 
An examination of the correlation matrix revealed a significant relationship between two sets of variables: (i) evaluations of country preparedness for the EURO 2012 (national pride and national shame) and (ii) emotional reactions to the game outcomes. Concerning the emotional reactions measured in wave\#2, national pride and national shame showed the strongest correlations with emotions after the PL-RU draw game. A little weaker correlations were found with the victory scale. These variables entered into significant relationships with the constructive coping scale in wave\#3. There were no significant correlations between national pride and national shame and emotions experienced after the defeat, neither when measured by counterfactual scale included in the second wave nor when measured by the factual final defeat scale in the third wave. Finally, emotions following counterfactual victory and defeat with Russia are strongly correlated, whereas draw-related emotions stand apart.

Next, path models to explain relationships between general and sport evaluations, anticipatory, and outcome-related emotions and behaviors across three waves of measures were tested. The first model has the final defeat as outcome variable (wave\#3). Its predictors from wave\#1 are interest in football and enthusiasm. Anticipatory emotions from wave 1 and the emotions after the imaginary defeat with Russia in wave 2 are the mediators. This model (see Fig. 2) shows indices of good overall fit $(X 2=16.6 ; \mathrm{df}=10 ; \mathrm{p}=0.09 ; \mathrm{NFI}=0.98 ; \mathrm{CFI}=0.99$ and $\mathrm{RMSEA}=0.03$ ).

Wave 1

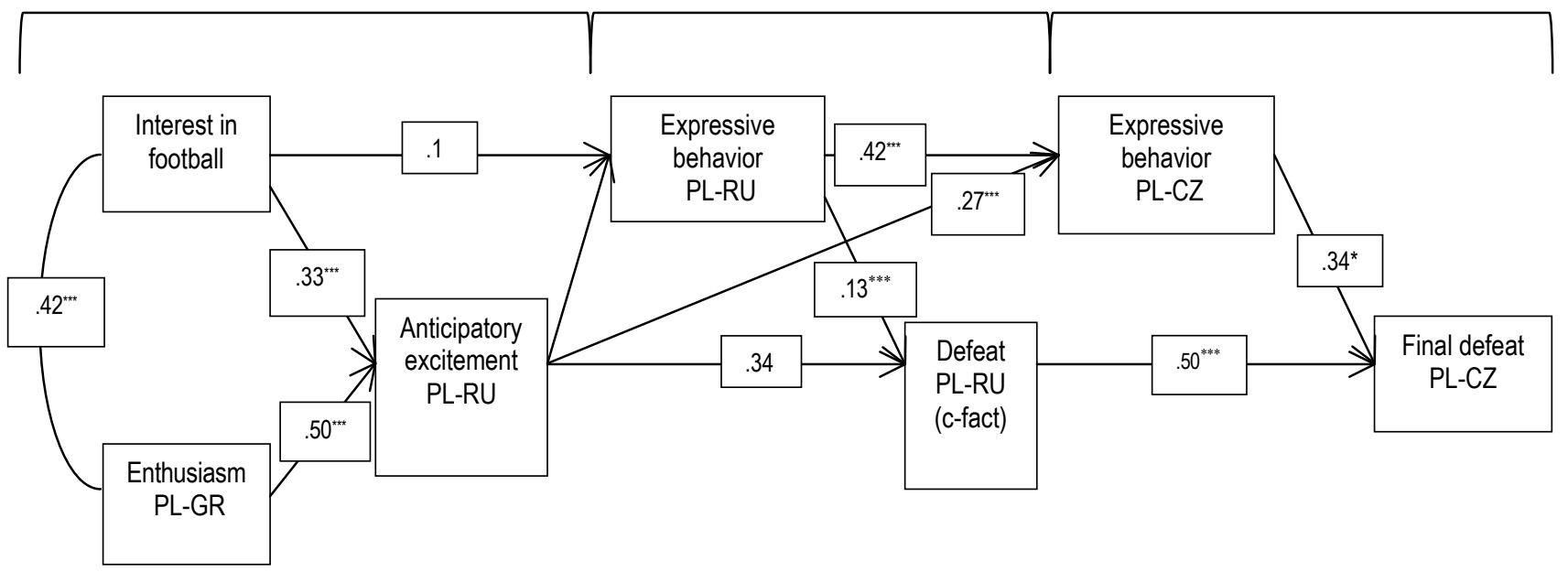

Fig. 2. Path model for the defeat

Note. The regression coefficients presented are standardized betas. Level of significance: ${ }^{* * *}=p<0.001 ;{ }^{* *}=p<0.01$.

Two path lines are seen in Fig. 2, leading from anticipatory PL-RU emotions to waves 2 and 3 consequences. First is through intensity of expressive behaviors, and the other through emotions accompanying an imaginary defeat with Russia. Expressive behaviors during matches are also directly related to the matches' outcome-related emotions. No good model for the victory was obtained.

Another wave 3 path model was obtained for constructive coping with the final defeat and dropping out of the tournament (see Figure 3). 


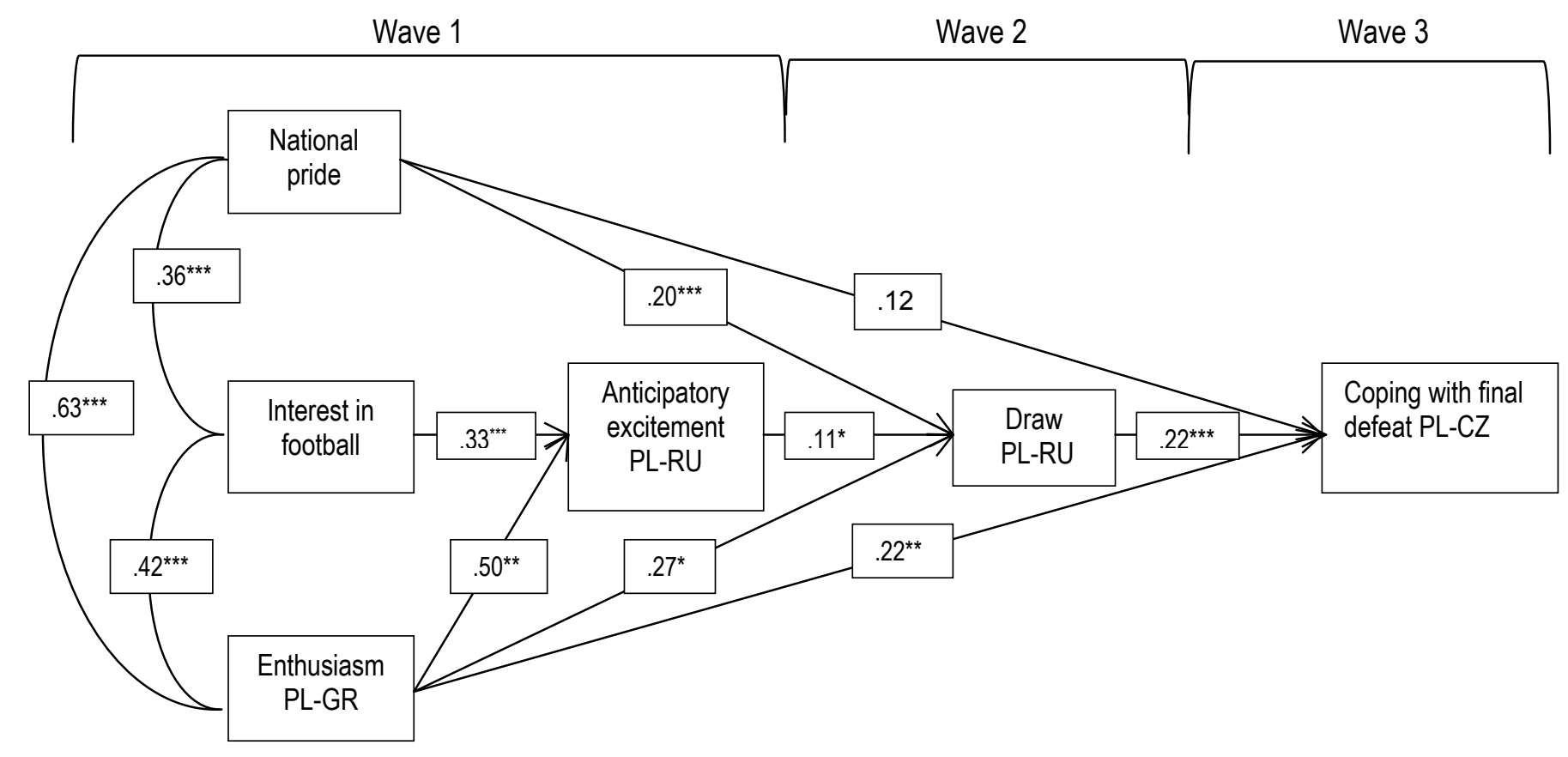

Fig. 3. Path model for the draw

Note. The regression coefficients presented are standardized betas. Level of significance: ${ }^{* * *}=p<0.001 ;{ }^{* *}=p<0.01 ;{ }^{*}=p<0.05$

The model showed good overall fit $(\mathrm{X} 2=7.1 ; \mathrm{df}=4 ; \mathrm{p}=0.13 ; \mathrm{NFI}=0.99 ; \mathrm{CFI}=0.99$ and RMSEA $=0.03$ ). In this case the central mediator was the scale of wave\#2 PL-RU draw-related emotions. It had two significant predictors from wave\#1: the opening game enthusiasm and national pride of EURO 2012. The relationship between interest in football and the draw was also mediated by PL-RU anticipatory excitement, but this path was much weaker than in the case of the first model concerning imaginary loss. Most essential is the link between PL-RU draw emotions in wave\#2 and constructive coping in wave\#3. Their antecedents are also similar: positive emotions of national pride and initial enthusiasm. Expressive behaviors did not fit into this model.

\section{Discussion}

The purpose of the present study was to explore spectator emotions during the 2012 UEFA European Football Championships. Special attention was paid to the local-Polish context of this event. The measures that we constructed served this purpose; they were all research bound. Regarding the atmosphere preceding and accompanying the tournament we wanted to investigate whether the appraisal of the final result of the five years of preparation process to the EURO would be associated with the sports emotions such as reaction to match scores. The data collected shows that such relations do exist. The more satisfied a person is with the state of preparation of the country to the event, the more intensive and positive emotions are experienced in response to the victory and draw of the national team. This positive link works with the constructive way of coping with the loss as well. The more a person is proud of the organization, the better his/her coping with the final defeat after the team's drop-out from the tournament.

An analogous negative relation is observed with the dissatisfaction. The more a person is dissatisfied and ashamed of the organization of the event, the less intense is the positive affect after the imagined victory or a draw (with Russia). There is no such relation between general EURO-2012 positivity and emotions experienced after a defeat, neither imaginary (to Russia), nor real (to Czech Republic). It looks as if general satisfaction with the championships reinforces positive game related emotions.

We have proposed a processual approach to emotions experienced by fans during sporttournament with a special focus on anticipatory emotions. We have hypothesized that the intensity 
of anticipatory emotions will be positively associated with the intensity of emotional reaction to the game result. This led to creation of a model concerning the predictors and correlates of emotions experienced by Polish fans during the three matches played by the Polish national team. The postulated paths turned out to be strong when the imaginary defeat in the Poland-Russia match was taken into consideration but not when reactions to the real draw score were analyzed. To best capture the specificity of draw-related emotions a second model was proposed. This model showed that the overall satisfaction with the tournament organization and enthusiasm about the tournament opening ceremony and the opening match are important predictors of draw-related emotions and of the coping optimism after the team dropped out. The excitement of the upcoming match does not play a distinctive role in this second model.

Cheering during the match, which expresses emotional involvement at the time when the game is being played, is unrelated to draw experience, contrary to the situation of a defeat. In the case of a lost match, pre-match excitement plays a significant role influencing the emotional reaction to the game outcome and it affects expressive behavior during the match. The number of activities undertaken while watching the match is directly related to the intensity of post-match emotions. The obtained models indicate that a draw is a qualitatively different experience than the loss. Defeat of a team is a highly emotional experience while a draw leads to more balanced reactions, constraining emotional display and keeping emotions under control. Being inconclusive as a game outcome, the meaning of a draw can be derived from the context; internally it conveys a meaning of emotional self-control. In the researched situation such an important context was the state-level preparation of the championship. Satisfaction from, and enthusiasm regarding the event facilitate also constructive coping after the team had been eliminated from further play. Thus, a draw bolsters ego-strength in dealing with reality evoking emotions. This is opposite to defeat and victory, when individuals and groups yield to strong emotions and are overwhelmed by them.

\section{Conclusions}

We did not manage to create a separate model explaining victory-related emotions. While the counterfactual scales were used to assess reactions to victory and defeat, the further development of the competition led to a real loss in the last group stage game and it constituted a logical causality chain by giving a real context to imaginary defeat emotions. This allowed for the creation of a model concerning the overall performance of the national team. No such natural prolongation of the victory-related emotions existed. Still, (imagined) victory seems to share more elements with defeat than with draw-related emotions; this remains to be tested in future studies.

\section{References}

1. Parkinson B, Fisher AH, Manstead ASR. Emotion in social relations. New York: Psychology Press; 2005.

2. Tajfel H. Some developments in European social psychology. European Journal of Social Psychology 1972;2:307-322.

3. Oglądalność Euro 2012 - 6,3 mln widzów fazy grupowej (raport) [in Polish] [Euro 2012 ratings - 6.3 million viewers of the group stage (the report)] [http://media2.pl/euro2012/93299-Ogladalnosc-Euro-201263-mln-widzow-fazy-grupowej-raport.html] [accessed on 16.01.2013]

4. Gibbons T. English national identity and the national football team: the view of contemporary English fans. Soccer \& Society 2011; 12:865-879.

5. Jones MV, Coffee P, Sheffield D, Yangüez M, Barker JB. Just a game? Changes in English and Spanish soccer fans' emotions in the 2010 World Cup. Psychology of Sport and Exercise 2012;13:162-169.

6. Atkinson JW. A theory of achievement motivation. New York: Wiley; 1966.

7. McClelland DC. Human motivation. Glennview: Scott, Foresman \& Co; 1985.

8. Boski P. Potrzeba osiagnięć a wzrost ekonomiczny [in Polish] [Achievement need and economic growth]. In: Reykowski J, editor. Osobowość a społeczne zachowanie ludzi [Peronality vs people's social behaviour]. Warszawa: KiW; 1980, 25-120.

9. Scherer KR. The role of culture in emotion-antecedent appraisal. Journal of Personality and Social Psychology 1997;7:902-922.

10. Kerr JH, Wilson GV, Nakamura I, Sudo Y. Emotional dynamics of soccer fans at winning and losing games. Pers Indiv Differ 2005;38:1855-1866. 
11. Wann DL, Dolan TJ, McGregor KK, Allison JA. Relationships between spectator identification and spectators' perception of influence, spectators' emotions and competition outcome. J Sport Exercise Psy 1994;14:347-364.

12. Wann DL, Royalty JL, Rochelle AR. Using motivation and team identification to predict sport fans' emotional response to team performance. Journal of Sport Behavior 2002;25:322-337.

13. Stott C, Adang O, Livingstone A, Schreiber M. Variability in the collective behaviour of England fans at Euro2004: 'Hooliganism', public order policing and social change. European Journal of Social Psychology 2007;37:75-100.

14. Gorący A. Zachowania agresywne kibiców [in Polish] [Fans' aggressive behavior]. In: Rychta T, Guszkowska M, editors. Wkład nauk humanistycznych do wiedzy o kulturze fizycznej [Humanistic sciences' contribution to the science of physical culture]. Warszawa: Polskie Towarzystwo Naukowe Kultury Fizycznej. Sekcja Psychologii Sportu; 2003, 191-196. 